\section{Towards a Framework for Assessing Daily Mobility Using GPS Data}

\author{
GI_Forum 2018, Issue 1 \\ Page: $177-183$ \\ Short Paper \\ Corresponding Author: \\ michelle.fillekes@geo.uzh.ch \\ DOI: 10.1553/giscience2018_01_s177
}

\author{
Michelle Pasquale Fillekes' ${ }^{1}$ Eleftheria Giannouli2 ${ }^{2}$, Wiebren Zijlstra ${ }^{2}$ and Robert Weibel ${ }^{1}$ \\ 'University of Zurich, Switzerland \\ ${ }^{2}$ German Sport University Cologne, Germany
}

\begin{abstract}
In health and aging studies that include GPS assessments, mobility is often represented by a single indicator such as the number of activity locations, the size of the activity space, or the total distance covered. We argue, however, that mobility is a multi-dimensional construct. In this paper, we first provide a framework to categorize and systematically organize daily-life mobility indicators. We then illustrate this framework by computing several mobility indicators based on GPS data recorded from healthy older adults. We apply a correlational approach to the computed mobility indicators as a first step towards discovering underlying dimensions of daily mobility. We found a trend towards higher correlations between mobility indicators that represent more similar properties of mobility. The framework can be used by health researchers to inform the choice of appropriate mobility indicators in the design of empirical studies.
\end{abstract}

\title{
Keywords:
}

healthy aging, framework, spatial activity, mobility indicator, real-life assessment

\section{Introduction}

In light of current demographic changes, it is important to study factors contributing to an active, independent and healthy lifestyle up to and into old age. An increasing number of studies have investigated the manifold relations between mobility and physical as well as psychological health, especially in older adults (Giannouli, Bock, \& Zijlstra, 2018; Kaspar, Oswald, Wahl, Voss, \& Wettstein, 2015; Rantakokko et al., 2015). However, most studies that found significant relations between mobility and health outcomes focus on the physical dimension of mobility (how much activity takes place) and less on its spatial dimension (where activity takes place). In this study, we are interested in this spatial dimension and define mobility as everyday spatio-temporal patterns of an individual's movements in their environment.

The study of daily mobility is important and can be related to various health outcomes for an individual in at least two ways (Chaix et al., 2013). Firstly, it provides information about the 
amount and modes of transportation used. Using active modes of transportation (e.g., walking, cycling) has a positive impact on physical activity levels and therefore also on health status. Further, the study of mobility can provide information about precise locations and thus the environments to which people are exposed. Environments can be beneficial (e.g., places for social interactions) or harmful to health and wellbeing (e.g., because of pollution). Yet studies often focus only on single aspects of mobility, such as modes of transportation (Takemoto et al., 2015), residential neighbourhood properties (Badland et al., 2009), or geometric properties of an individual's activity space (Hirsch, Winters, Clarke, \& McKay, 2014). In contrast, we agree with Perchoux et al. (2014) and suggest that mobility is a complex, multi-dimensional construct which should be assessed as comprehensively as possible, before relating it to different health outcomes. Combining daily-life GPS assessments with contextual information is one way of collecting information on multiple aspects of mobility and the resulting environmental exposure. Comparable attempts in the literature to classify mobility indicators have typically focused on a few specific aspects of mobility and do not characterize a diverse set of mobility indicators (e.g., Brusilovskiy, Klein, \& Salzer, 2016; Perchoux et al., 2014).

The aim of this paper is to provide a framework for classifying mobility indicators that represent different aspects of an individual's mobility patterns and their environment, with the intention of providing guidelines regarding the choice of appropriate mobility indicators in empirical health studies. GPS data of 87 healthy older adults were processed to compute a subset of indicators. A correlational approach was then applied to the computed mobility indicators as a first step towards discovering underlying dimensions of daily mobility.

\section{Categorization of GPS-based daily mobility indicators}

Table 1 shows a summary of the proposed framework to categorize mobility indicators describing various dimensions of individuals' mobility and environmental exposure based on GPS data. The indicators presented in the table are exemplary and no claim to exhaustiveness is made. First, we group mobility indicators according to the movement scope they are referring to: 'stops', 'moves' or 'activity space'. These categories are inspired by computational movement analysis, in which it is common to segment spatio-temporal trajectories into stops (so-called activity locations or static behaviour) and moves (dynamic behaviour) (Laube, 2014; Siła-Nowicka et al., 2016). The stops and moves can subsequently be analysed separately. Activity space (in health research also referred to as life space) describes the overall distribution of the spatial locations corresponding to an individual's exhaustive spatial footprint (Chaix et al., 2012). Second, each indicator categorized among one of the movement scope categories can be assigned to one of four further categories - 'spatial structure', 'temporal structure', 'nature of activity' or 'exposure' - representing different aspects of mobility that may be of interest. The first three categories are derived directly from the three intertwined components of spatial behaviour presented in Chaix et al. (2013). 'Spatial structure' refers to geometrical aspects of mobility, including the spatial extent and shape of the movement. 'Temporal structure' refers to the duration of different spatial activities, regularity / variability in mobility patterns, or even to the circadian rhythm inherent in a person's mobility. 'Nature of activity' refers to the semantics of the mobility 
patterns proper, e.g. mode of transportation or types of activity locations visited. 'Exposure', the last of the proposed categories, is strongly interlinked with mobility, as it defines where (spatial structure), when and how long (temporal structure), and how (nature of activity) people are exposed to different environments (e.g. built/natural/social) (Chaix et al., 2012). To extract this type of information, additional information is needed. This additional information can be extracted from GIS data provided by, for example, OSM (openstreetmap.org), using additional sensors (audio, visual), or using self-reported data from participants. Depending on the research context and the available data, mobility indicators can be computed for different temporal granularities, including hourly, daily, weekly or even event-based resolutions.

Table 1: Framework for classifying mobility indicators describing individuals' mobility and environmental exposure according to the movement scope and the investigated aspect. As an illustration, we classified a selected set of GPS-based indicators according to these two dimensions. The ones shown in bold were computed for this paper.*

\begin{tabular}{|c|c|c|c|c|c|}
\hline & \multicolumn{5}{|c|}{ Aspect } \\
\hline \multirow{4}{*}{ 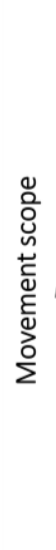 } & & $\begin{array}{l}\text { Spatial structure } \\
\text { Where? (extent, spatial } \\
\text { distribution) }\end{array}$ & $\begin{array}{l}\text { Temporal structure } \\
\text { When? How long? } \\
\text { (sequence, variability) }\end{array}$ & $\begin{array}{l}\text { Nature of activity } \\
\text { How? (mode) }\end{array}$ & $\begin{array}{l}\text { Exposure } \\
\text { What? (environmental/ } \\
\text { contextual exposure) }\end{array}$ \\
\hline & $\begin{array}{l}\text { Stops } \\
\text { (activity } \\
\text { locations) }\end{array}$ & $\begin{array}{l}\text { - (1) Number of activity } \\
\text { locations }{ }^{[1]} \\
\text { - Distribution of activity } \\
\text { locations }\end{array}$ & $\begin{array}{l}\text { - Time spent in activity } \\
\text { locations } \\
-(6) \text { Entropy in activity } \\
\text { locations }^{[2]}\end{array}$ & $\begin{array}{l}\text { - Types of activity } \\
\text { location (indoor vs. } \\
\text { outdoor, home, work } \\
\text { etc.) }\end{array}$ & $\begin{array}{l}\text { - Residential environment } \\
\text { (e.g., connectivity) }\end{array}$ \\
\hline & $\begin{array}{l}\text { Moves } \\
\text { (displacements } \\
\text { between activity } \\
\text { locations) }\end{array}$ & - (2) Distance ${ }^{[2]}$ & $\begin{array}{l}\text { - Time spent travelling } \\
\text { - Regularity in travelling } \\
\text { patterns (with respect } \\
\text { to time of day or } \\
\text { duration) }\end{array}$ & $\begin{array}{l}\text { - Mode of transport (e.g., } \\
\text { active vs. passive) })^{[7]}\end{array}$ & $\begin{array}{l}\text { - Exposure to } \\
\text { environment (built, } \\
\text { natural, social) along } \\
\text { displacements }{ }^{[8]}\end{array}$ \\
\hline & $\begin{array}{l}\text { Activity Space } \\
\text { (entire spatial } \\
\text { footprint) }\end{array}$ & $\begin{array}{l}\text { - (3) Area of convex hull } \\
\text { or standard deviational } \\
\text { ellipse }{ }^{[3]} \\
\text { - (4) Mean / (5) maximum } \\
\text { action range (AR) }{ }^{[4]}\end{array}$ & $\begin{array}{l}\text { - (7) Time out of home } \\
(\text { TOOH })^{[2]} \\
\text { - Temporal category at } \\
\text { maximum AR }{ }^{[5]} \\
\text { - Overlap between daily } \\
\text { convex hulls }\end{array}$ & $\begin{array}{l}\text { - Ratio between } \\
\text { stationary and mobile } \\
\text { phases }\end{array}$ & $\begin{array}{l}\text { - Exposure throughout } \\
\text { the entire activity space } \\
\text { - (8) Exposure to nature }{ }^{|9|}\end{array}$ \\
\hline
\end{tabular}

*Note. The references within the table are to: Montoliu, Blom \& Gatica-Perez (2013); Saeb, Lattie, Schueller, Kording, \& Mohr (2016); Hirsch, Winters, Clarke, \& McKay (2014); Giannouli, Bock, \& Zijlstra (2018); Klous et al. (2017); Perchoux et al. (2014); Takemoto et al. (2015); Cetateanu et al. (2016), Dewulf et al. (2016).

\section{Case study}

\section{Pre-processing of GPS data}

We used the same GPS data as Giannouli et al. (2016) for a group of healthy adults aged over 65 to exemplarily compute and analyse a subset of the mobility indicators shown in Table 1. The study's inclusion criteria required participants to be healthy - i.e., all were community dwelling, did not use any walking aid, and did not suffer from any acute neurological or orthopedic diseases.

The dataset consists of a sample of approximately one week of GPS data as well as the home location of each participant. After pre-processing the GPS data (outlier removal, day 
segmentation), we retained only participants for whom we had data covering at least 3 participant-days (each $\geq 8$ hours), and a valid home address (distance between GPS-derived home and reported home address $\leq 150 \mathrm{~m}$ ). Thus, the original dataset consisting of 86 participants and 597 participant-days was reduced to 50 participants and 283 participantdays.

\section{Selection and computation of mobility indicators}

Table 2 shows the mobility indicators computed for each participant-day of the study sample (except for normalized entropy, which is a weekly indicator). We intentionally chose a subset of eight indicators (shown in bold in Table 1) relating to different categories of the two dimensions movement scope and aspect. Indicators 1 to 5 may be categorized as relating to the 'spatial structure' of mobility behaviour, whereas the computation of Indicator 1 is based on 'stops', Indicator 2 on 'moves', and Indicators 3-5 on the overall daily mobility pattern and thus on the category 'activity space'.

Indicators 6 and 7 refer to the 'temporal structure' of mobility. The former is based on the 'stop' locations and the latter on the entire set of GPS locations and is therefore included in the 'activity space' category. Indicator 8 also refers to the 'activity space' category and represents the final aspect, 'exposure', because it provides information about an individual's context.

Table 2: Computed mobility indicators

\begin{tabular}{ll}
\hline Mobility indicator & Calculation \\
\hline (1) Number of activity & $\begin{array}{l}\text { Number of ALs (except for home), detected using stay } \\
\text { point algorithm by Montoliu et al. (2013) with time } \\
\text { locations (ALs) }\end{array}$ \\
& m. \\
& Trajectory length. \\
(2) Distance & Convex hull around all GPS fixes. \\
(3) Area of convex hull & Mean straight-line distance from home to GPS fixes. \\
(4) Mean action range (AR) & Maximum straight-line distance from home to GPS \\
(5) Max. AR & fixes. \\
& Time distributed over different ALs (except for home) \\
(6) Normalized entropy & computed as in Saeb et al. (2016). High entropy \\
& indicates that the participant spent time more \\
& uniformly across different ALs. \\
& Sum of durations between GPS fixes classified as 'out \\
& of home' $\geq 150$ m). Gaps of up to 1 hour were \\
(7) Time out of home & interpolated, if previous and subsequent GPS fix were \\
(TOOH) & both out of home. \\
& Ratio of GPS fixes within CORINE land cover classes \\
(8) Exposure to nature & representing natural environments (European \\
& Environment Agency, 2018). \\
\hline
\end{tabular}




\section{Results}

Table 3 shows the mean $(m)$ and standard deviation $(s d)$ for the computed subset of mobility indicators.

Table 3: Statistics for the mobility indicators of each individual's registration period

\begin{tabular}{lr}
\hline Mobility Indicator & {$[m(s d)]$} \\
\hline (1) Average daily number of ALs & $3.23(1.63)$ \\
(2) Average daily distance $[\mathrm{km}]$ & $23.70(13.31)$ \\
(3) Average daily area of convex hull $\left[\mathrm{km}^{2}\right]$ & $18.03(23.02)$ \\
(4) Average daily mean AR $[\mathrm{km}]$ & $2.57(2.48)$ \\
(5) Average daily max. AR $[\mathrm{km}]$ & $6.37(5.19)$ \\
(6) Weekly normalized entropy $[0-1]$ & $0.52(0.22)$ \\
(7) Average daily TOOH [min] & $148.75(69.76)$ \\
(8) Average daily exposure to nature [0-1] & $0.16(0.15)$ \\
\hline
\end{tabular}

Table 4 presents the correlation values for the mobility indicators. It shows that Indicators 2 to 5 (representing the 'spatial structure' aspect and 'move' or 'activity space' categories) are all highly correlated (0.82-0.93). Indicator 1 , which also covers the aspect of 'spatial structure' but for the movement scope of 'stops', is also correlated with the 'spatial structure' Indicators 2 to 5 . The number of ALs gives an indication of how many different activities an individual might be engaged in, which is not directly related to how much space an individual covers. No significant correlations with the remaining indicators were found for the normalized entropy (Indicator 6). How time is allocated to different ALs does not therefore seem to be related to either the spatial structure or the temporal duration of mobility. The correlation between $\mathrm{TOOH}$ and the other indicators representing the 'spatial structure' of mobility is moderate to high $(0.40-0.75)$. The two highest correlation values amongst them were for Indicators 1 (number of ALs) and 2 (distance). This can be attributed to the fact that both describe, rather, the amount of moving through space, which may be independent of the spatial extent of the mobility. Finally, exposure to nature (8) seems to be moderately $(0.29-0.51)$ related to all other indicators representing spatial and temporal aspects of mobility, except for the entropy indicator.

Table 4: Associations between the mobility indicators*

\begin{tabular}{lrrrrrrr}
\hline Mobility Indicator & $\mathbf{( 2 )}$ & $\mathbf{( 3 )}$ & $\mathbf{( 4 )}$ & $\mathbf{( 5 )}$ & $\mathbf{( 6 )}$ & $\mathbf{( 7 )}$ & $\mathbf{( 8 )}$ \\
\hline (1) Number of ALs & $\mathbf{0 . 5 5}$ & $\mathbf{0 . 4 8}$ & $\mathbf{0 . 4 1}$ & $\mathbf{0 . 3 9}$ & 0.17 & $\mathbf{0 . 7 5}$ & $\mathbf{0 . 2 9}$ \\
(2) Distance & - & $\mathbf{0 . 9 1}$ & $\mathbf{0 . 8 2}$ & $\mathbf{0 . 9 2}$ & 0.02 & $\mathbf{0 . 5 8}$ & $\mathbf{0 . 4 6}$ \\
(3) Area of convex hull & - & - & $\mathbf{0 . 9 1}$ & $\mathbf{0 . 9 3}$ & -0.09 & $\mathbf{0 . 4 7}$ & $\mathbf{0 . 4 9}$ \\
(4) Mean AR & - & - & - & $\mathbf{0 . 9 3}$ & 0.05 & $\mathbf{0 . 4 8}$ & $\mathbf{0 . 5 1}$ \\
(5) Max. AR & - & - & - & - & 0.00 & $\mathbf{0 . 4 0}$ & $\mathbf{0 . 4 7}$ \\
(6) Normalized entropy & - & - & - & - & - & 0.22 & 0.17
\end{tabular}


*Note. Spearman's correlation coefficients were computed. According to the Shapiro-Wilk normality test, the variables were not normally distributed. Correlation coefficients in bold are significant at $\mathrm{p}<0.05$.

\section{Discussion and Conclusion}

We have introduced a framework to categorize different mobility indicators along the two dimensions movement scope and aspect of mobility activities. In a preliminary case study, we computed mobility indicators for a group of 50 healthy older adults using various categories along these two dimensions. Correlation analysis shows that indicators relating to more similar properties of mobility (partially reflected by the aspect category of the framework presented) are more closely associated with each other. However, the various categories may still feature indicators reflecting very different aspects of mobility. This is shown, for example, by TOOH and normalized entropy, which both represent temporal structures of mobility. The former, however, refers more to the duration of mobility, whereas the latter refers to how time was spent throughout different activity locations.

The suggested framework highlights the breadth of aspects that can be looked at when studying human mobility in a health context. Inspired by work from computational movement analysis, the framework further suggests on which category along the movement scope dimension the computation of the indicators can be based. In future research, we plan to compute a more complete set of mobility indicators for the proposed framework, before carrying out dimensionality reduction to uncover the underlying dimensions of mobility. This could inform the choice in empirical studies of a minimal set of mobility indicators that reflect as closely as possible the most important dimensions of individuals' mobility behaviour.

\section{References}

Badland, H. M., Schofield, G. M., Witten, K., Schluter, P. J., Mavoa, S., Kearns, R. a, ... McPhee, J. (2009). Understanding the relationship between activity and neighbourhoods (URBAN) study: research design and methodology. BMC Public Health, 9(224). http://doi.org/10.1186/1471-24589-224

Brusilovskiy, E., Klein, L. A., \& Salzer, M. S. (2016). Using global positioning systems to study healthrelated mobility and participation. Social Science and Medicine, 161, 134-142. http://doi.org/10.1016/j.socscimed.2016.06.001

Cetateanu, A., Luca, B.-A., Popescu, A. A., Page, A., Cooper, A., \& Jones, A. (2016). A novel methodology for identifying environmental exposures using GPS data. International Journal of Geographical Information Science, 8816(February), 1-17. http://doi.org/10.1080/13658816.2016.1145682

Chaix, B., Kestens, Y., Perchoux, C., Karusisi, N., Merlo, J., \& Labadi, K. (2012). An interactive mapping tool to assess individual mobility patterns in neighborhood studies. American Journal of Preventive Medicine, 43(4), 440-450. http://doi.org/10.1016/j.amepre.2012.06.026 
Chaix, B., Méline, J., Duncan, S., Jardinier, L., Perchoux, C., Vallée, J., ... Kestens, Y. (2013). Neighborhood environments, mobility, and health: towards a new generation of studies in environmental health research. Revue d'Épidémiologie et de Santé Publique, 61, 139-145. http://doi.org/10.1016/j.respe.2013.05.017

Dewulf, B., Neutens, T., Van Dyck, D., de Bourdeaudhuij, I., Broekx, S., Beckx, C., \& Van de Weghe, N. (2016). Associations between time spent in green areas and physical activity among late middleaged adults. Geospatial Health, 11(3), 225-232. http://doi.org/10.4081/gh.2016.411

European Environment Agency, (EEA). (2018). CORINE land cover V18.5. Retrieved March 8, 2018, from https://land.copernicus.eu/

Giannouli, E., Bock, O., Mellone, S., \& Zijlstra, W. (2016). Mobility in old age: capacity is not performance. BioMed Research International, 2016 (February). http://doi.org/10.1155/2016/3261567

Giannouli, E., Bock, O., \& Zijlstra, W. (2018). Cognitive functioning is more closely related to real-life mobility than to laboratory-based mobility parameters. European Journal of Ageing, 1-9. http://doi.org/10.1007/s10433-017-0434-3

Hirsch, J. A., Winters, M., Clarke, P., \& McKay, H. (2014). Generating GPS activity spaces that shed light upon the mobility habits of older adults: a descriptive analysis. International Journal of Health Geographics, 13(1), 51. http://doi.org/10.1186/1476-072X-13-51

Kaspar, R., Oswald, F., Wahl, H.-W., Voss, E., \& Wettstein, M. (2015). Daily mood and out-of-home mobility in older adults. Journal of Applied Gerontology, 34(1), 26-47. http://doi.org/10.1177/0733464812466290

Klous, G., Smit, L. A. M., Borlée, F., Coutinho, R. A., Kretzschmar, M. E. E., Heederik, D. J. J., \& Huss, A. (2017). Mobility assessment of a rural population in the Netherlands using GPS measurements. International Journal of Health Geographics, 16(1), 30. http://doi.org/10.1186/s12942017-0103-y

Laube, P. (2014). Computational movement analysis. Springer Handbook of Geographic Information. http://doi.org/10.1007/978-3-540-72680-7_22

Montoliu, R., Blom, J., \& Gatica-Perez, D. (2013). Discovering places of interest in everyday life from smartphone data. Multimedia Tools and Applications, 62(1), 179-207. http://doi.org/10.1007/s11042011-0982-z

Perchoux, C., Kestens, Y., Thomas, F., Hulst, A. Van, Thierry, B., \& Chaix, B. (2014). Assessing patterns of spatial behavior in health studies: their socio-demographic determinants and associations with transportation modes (the RECORD Cohort Study). Social Science and Medicine, 119, 64-73. http://doi.org/10.1016/j.socscimed.2014.07.026

Rantakokko, M., Portegijs, E., Viljanen, A., Iwarsson, S., Kauppinen, M., \& Rantanen, T. (2015). Changes in life-space mobility and quality of life among community-dwelling older people: a 2-year follow-up study. Quality of Life Research. http://doi.org/10.1007/s11136-015-1137-x

Saeb, S., Lattie, E. G., Schueller, S. M., Kording, K. P., \& Mohr, D. C. (2016). The relationship between mobile phone location sensor data and depressive symptom severity. PeerJ, 4, e2537. http://doi.org/10.7717/peerj.2537

Siła-Nowicka, K., Vandrol, J., Oshan, T., Long, J. A., Demšar, U., \& Fotheringham, A. S. (2016). Analysis of human mobility patterns from GPS trajectories and contextual information. International Journal of Geographical Information Science, 30(5), 881-906. http://doi.org/10.1080/13658816.2015.1100731

Takemoto, M., Carlson, J. A., Moran, K., Godbole, S., Crist, K., \& Kerr, J. (2015). Relationship between objectively measured transportation behaviors and health characteristics in older adults. International Journal of Environmental Research and Public Health, 12(11), 13923-13937. http://doi.org/10.3390/ijerph121113923 